\title{
Investigation of the Novel Lead of Melanocortin 1 Receptor for Pigmentary Disorders
}

\author{
Hsin-Chieh Tang ${ }^{1}$ and Calvin Yu-Chian Chen ${ }^{2,3,4,5}$ \\ ${ }^{1}$ Department of Biomedical Informatics, Asia University, Taichung 41354, Taiwan \\ ${ }^{2}$ Department of Medicine, China Medical University, Taichung 40402, Taiwan \\ ${ }^{3}$ Department of Biotechnology, Asia University, Taichung 41354, Taiwan \\ ${ }^{4}$ China Medical University Beigang Hospital, Yunlin 65152, Taiwan \\ ${ }^{5}$ Computational and Systems Biology, Massachusetts Institute of Technology, Cambridge, \\ MA 02139, USA \\ Correspondence should be addressed to Calvin Yu-Chian Chen; ycc929@mit.edu
}

Received 18 November 2013; Revised 15 December 2013; Accepted 15 December 2013; Published 17 February 2014

Academic Editor: Fuu-Jen Tsai

Copyright $\odot 2014$ H.-C. Tang and C.-C. Chen. This is an open access article distributed under the Creative Commons Attribution License, which permits unrestricted use, distribution, and reproduction in any medium, provided the original work is properly cited.

\begin{abstract}
Knowing the role of MC1R in skin tanning can provide a brand new idea to resolve pigmentary disorders. $\alpha \mathrm{MSH}$ has 13 amino acids and is the most essential pigmentary melanocortin responsible for melanin synthesis. One could utilize the compound library to find lead compounds by virtual screening from peptide database and traditional Chinese medicine (TCM) database@Taiwan. Computational simulation provided a convenient technology to survey potential lead. Ligand-based validation set up the reliable model for molecular dynamics simulation. Molecular dynamics simulation approved the binding affinity and stability of the peptides selected by virtual screening. Thus, we concluded that Glu-Glu-Lys-Glu (EEKE), Glu-Gly-Gly-Ser-Val-Glu-Ser (EGGSVES), and Glu-Glu-Asp-Cys-Lys (EEDCK) were potent lead peptides for MC1R to resolve pigmentary disorders.
\end{abstract}

\section{Introduction}

Excessive melanin contributes to skin tanning or darkening. Ultraviolet (UV) radiation leads to skin pigmentation by manufacturing melanin in the melanocytes located at the basal layer of epidermis. Expression of the proopiomelanocortin (POMC) gene producing $\alpha$-melanocyte stimulating hormone $(\alpha \mathrm{MSH})$ takes place in keratinocytes. $\alpha \mathrm{MSH}$ recognizing melanocortin 1 receptor (MC1R) located on the cell membrane of melanocytes starts a series of signal pathways [1]. The $\alpha \mathrm{MSH} / \mathrm{MClR}$ triggers downstream signal transduction which is followed by cyclic adenosine monophosphate (cAMP), protein kinase A (PKA), and cAMP responsive element binding protein/cAMP responsive element (CREB/CRE) pathway [2]. Microphthalmia-associated transcription factor (MITF) begins its function in turn. It is an important protein that controls the activation of following melanotic genes: tyrosinase and tyrosinase related protein 1 and 2 (Trp1 and Trp2) [3, 4].
MSHs belong to the POMC hormone groups and include three types of $\alpha, \beta$, and $\gamma$-MSH [5]. Generally speaking, $\alpha \mathrm{MSH}$ is a pituitary peptide hormone derived from adrenocorticotropic hormone (ACTH) [6]. $\alpha \mathrm{MSH}$ which affects skin pigmentation mainly produces locally instead of pituitary origin [7]. $\alpha \mathrm{MSH}$ has 13 amino acids and is the most essential pigmentary melanocortin responsible for melanin synthesis or melanogenesis [8]. Its amino acid sequences are Ser-Tyr-Ser-Met-Glu-His-Phe-Arg-Trp-Gly-Lys-Pro-Val [9]. Synthetic analogs of $\alpha \mathrm{MSH}$ have been developed as useful probes binding to the melanocortin receptor or MClR which is overexpressed in melanoma lesions [10, 11]. His6Phe7-Arg8-Trp9 (HFRW) is the most common active motif approved in the literature [12, 13]. Experimental order exchange of $\alpha \mathrm{MSH}$ had been demonstrated as high-affinity peptides binding to the MClR but loss of their agonistic function [14].

Melanocortin receptors belong to class A or rhodopsin of the superfamily of 7-transmembrane G protein-coupled 


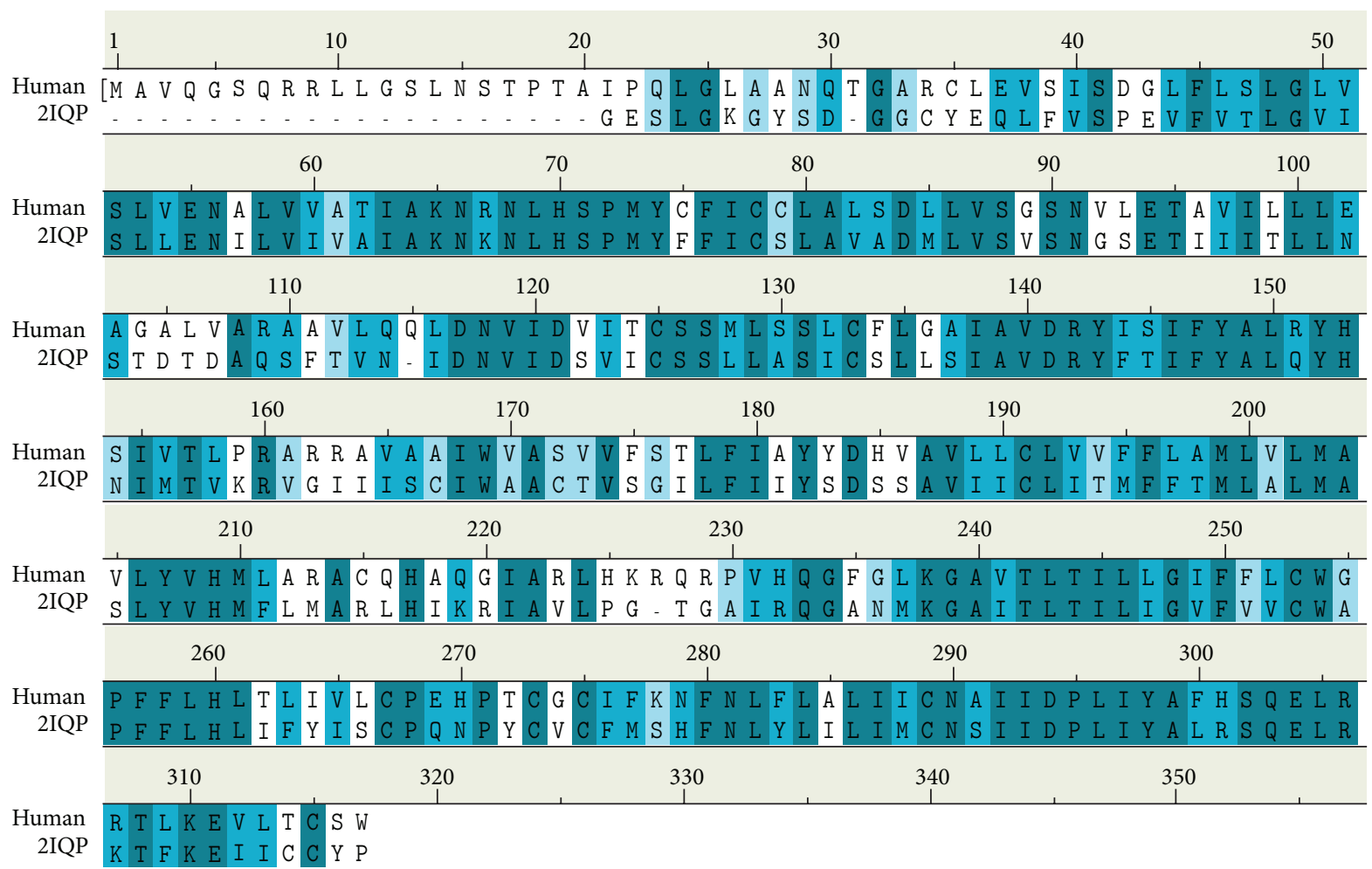

FIGURE 1: Sequence alignment between MC1R_human and template (2IQP). The identity is $49.8 \%$ and the similarity is $72.4 \%$.

receptors (GPCRs) [15-17]. GPCR receives external signal, for example, hormones and neurotransmitters, vary in molecular size from small peptides to large proteins [18]. There are five known melanocortin receptors, MC1 5R [19]. They have similar structure conformation but participate in unique physiologic functions: pigmentation, adrenal function, cardiovascular regulation, obesity or energy homeostasis, and exocrine gland secretion [20, 21]. MClR is the irreplaceable target involved in regulating our skin or hair color [22]. The coat color of animals or plumage color of birds is also regulated by MClR gene [23, 24]. MC1R has 318 amino acids; $\alpha \mathrm{MSH}$ is its agonist, and agouti signal protein is its antagonist. They determine the phenotype of our skin and hair by producing black, brown eumelanin or yellow, red pheomelanin [25].

Protein sequence and structure analysis by computational simulation have become popular technology in recent decades $[26,27]$. We use computational systems biology or in silico biology to research the protein-molecule or the protein-ligand interaction [28, 29]. Drug discovery integrates systems biology and informatics called computer-aided drug design (CADD) [30, 31]. The advantages of CADD techniques shorten our time to find appropriate drug compound opposite to traditional biochemistry [32, 33]. Quantitative structure activity relationship in silico can tell us the properties between small molecule and target protein [34]. Virtual screening and validations through structure-based or ligandbased analysis constitute to CADD procedures $[35,36]$. Virtual screening and data analysis utilize docking and molecular dynamics (MD) simulation [37-39]. How long the compound needs to form stable complex structure with target protein can be predicted by MD [40]. Docking and MD accuracy is relying on a series of statistic or score systems [41]. Ligand-based analysis utilizes mathematical model such as Bayesian algorithm $[42,43]$. We can choose best candidates from virtual screening and validations as potential effective drugs [44].

Knowing the role of $\mathrm{MClR}$ in skin tanning can provide a brand new idea to prevent UV darkening [45]. Clinical application of $\alpha \mathrm{MSH}$ analog is significant in managing certain dermatologic diseases [46]. CADD has been rapidly applied in small molecular drug design [47-50]. Virtual screening of compound database becomes the first and convenient way for CADD [51-56]. Screening peptides for compounds as a drug is a method to design antimicrobial peptides and potent peptides for peptide receptors, such as GPCRs [5759]. MC1R is a peptide receptor, and peptide design for its agonist and antagonist can be achieved [60]. Virtual screening from peptide database and traditional Chinese medicine (TCM) database@Taiwan in silico saves our time to filter the functional compounds [61-63]. We attempted to investigate the lead for MCIR to resolve pigmentary disorders.

\section{Materials and Methods}

2.1. Compound Database. To investigate lead peptides of MCIR from peptide library, we downloaded all the peptides from PepBank (http://pepbank.mgh.harvard.edu/) to conduct MC1R lead peptide screening [64]. 

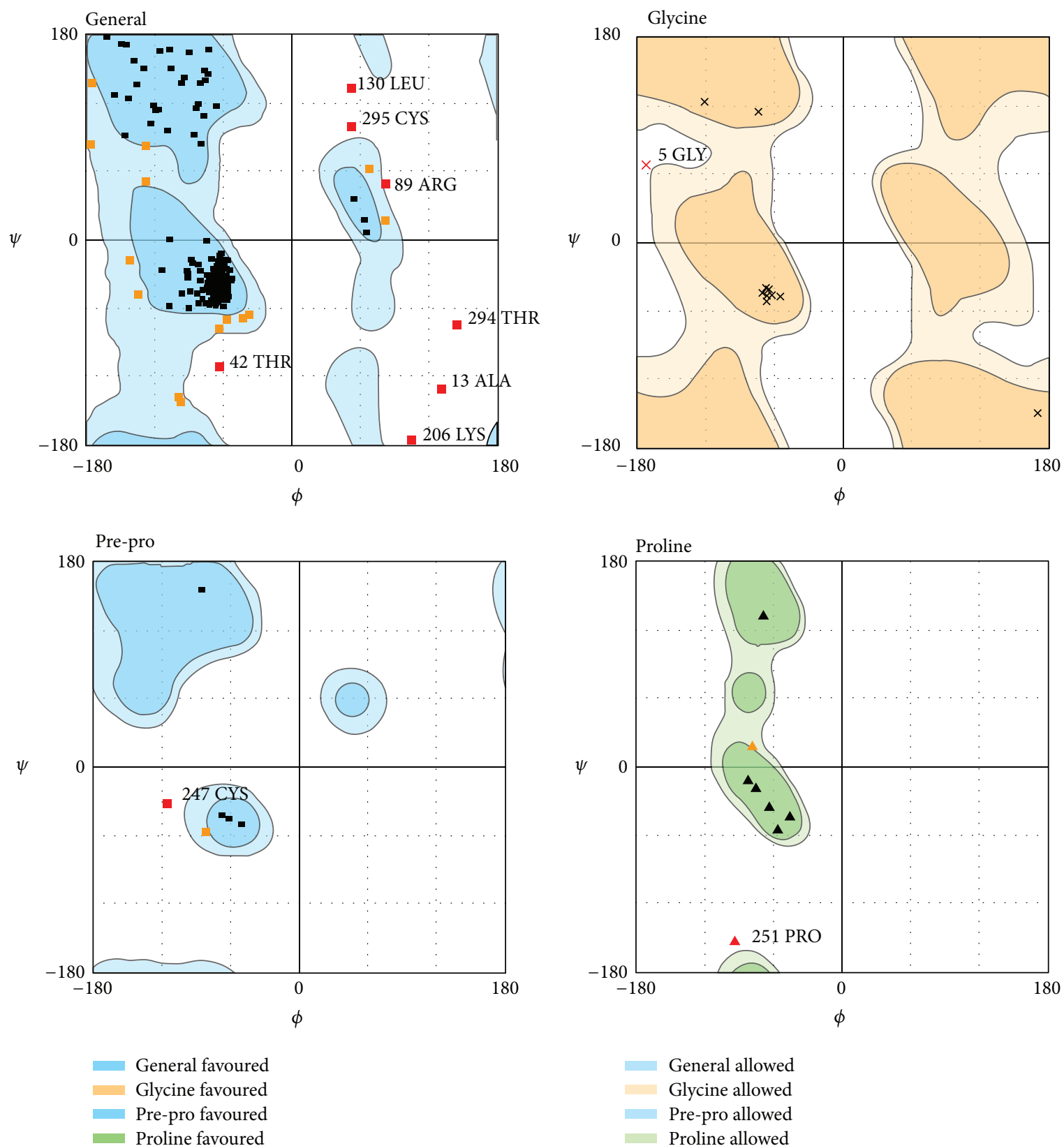

FiguRE 2: Ramachandran plot of MC1R-modeled structure. Number of residues in favored region ( 98.0\% expected): 444 (84.7\%). Number of residues in allowed region ( 2.0\% expected): 52 (9.9\%). Number of residues in disallowed region: 28 (5.3\%).

2.2. Data Collection. For the purpose of identifying MC1R lead peptides, we obtained the structures and corresponding bioactivities $\left(\mathrm{pIC}_{50}\right)$ of 18 peptides to construct the data set for ligand-based prediction [65].

2.3. Homology Modeling. The MC1R protein sequence was acquired from the Uniprot Knowledgebase (Q01726, MC1R_Human). The 3D structure of human MC4R was acquired from Protein Data Bank (PDB ID: 2IQP). MC1R sequence and the template structure were aligned by Discovery Studio (DS) 2.5. The rational MC1R model was further examined by Ramachandran plot [66].
2.4. Structure-Based Virtual Screening. The ligands from PepBank and the control ligand, His-Phe-Arg-Trp (HFRW), were prepared for specified modeling methods. We used Chemistry at HARvard Molecular Mechanics (CHARMm) force field to set up the model [67]. Docking and scoring functions were estimated by LigandFit module in DS 2.5. We applied the scoring functions including Dock Score, piecewise linear potentials (-PLP), and potential of mean force (-PMF) $[47,50]$.

2.5. Ligand-Based Validation. Bayesian network constructed the property of descriptors by integrating the data of training 
<smiles>NCCCC[C@H](NC(=O)[C@H](CCC(=O)[O-])NC(=O)[C@H](N)CCC(=O)[O-])C(=O)N[C@@H](C=O)CCC(=O)[O-]</smiles>

(a)<smiles>NC(=O)[C@@H]([NH3+])CCC(=O)[O-]</smiles><smiles>C[C@H](CCC(=O)[O-])C(=O)N[C@@H](CC(=O)[O-])C(=O)N[C@@H](CS)C(=O)N[C@H](C=O)CCCC[NH3+]</smiles>

(c)

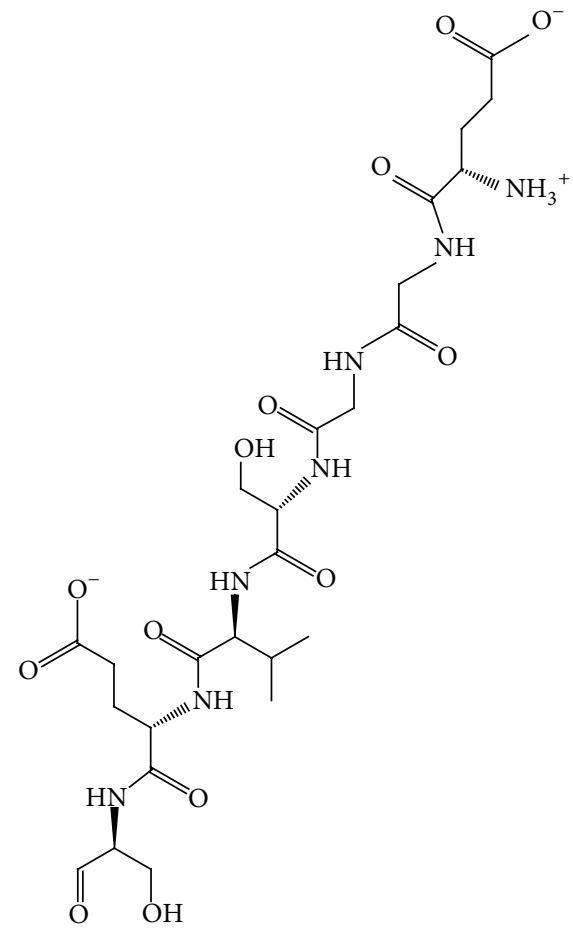

(b)

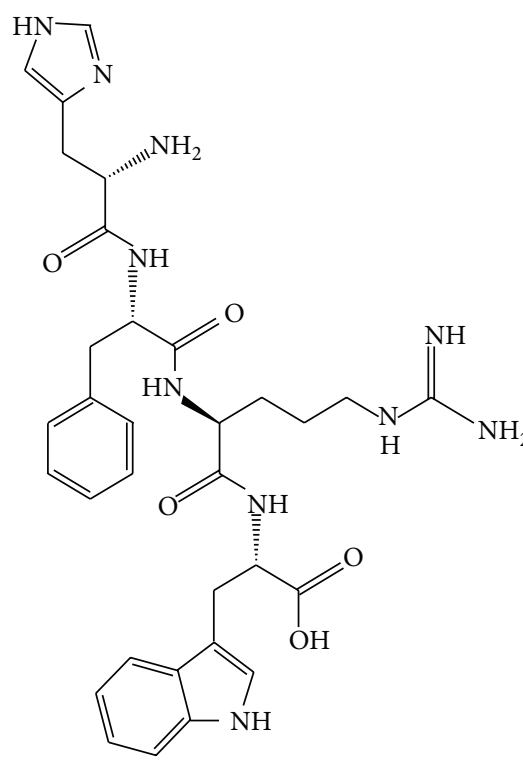

(d)

FIGURE 3: Scaffold of top 3 candidate peptides: (a) EEKE, (b) EGGSVES, (c) EEDCK, and the control: (d) HFRW. 


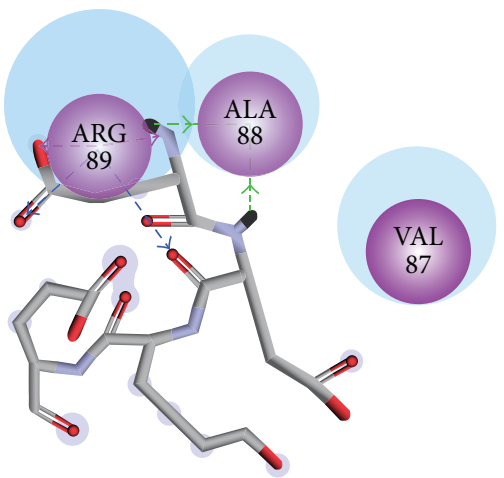

(a)

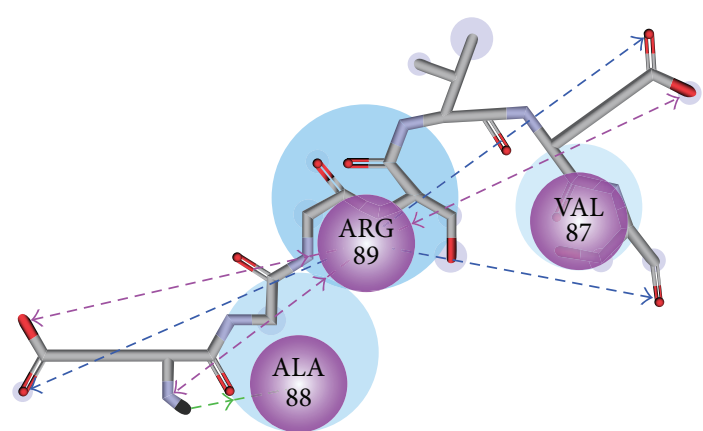

(b)

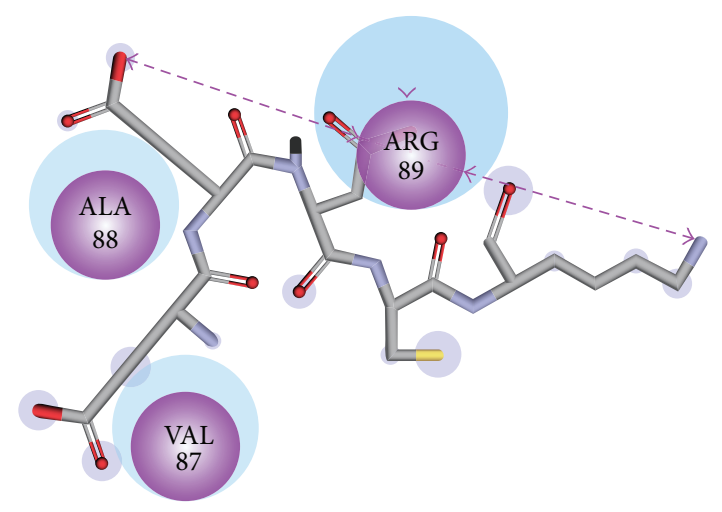

(c)

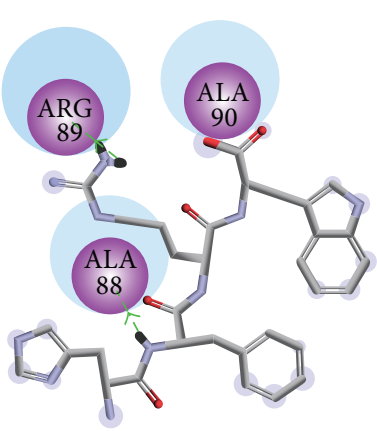

(d)

Figure 4: Docking poses of (a) EEKE, (b) EGGSVES, (c) EEDCK, and (d) HFRW. Purple sphere: Residues involved in hydrogen bond (Hbond) or charge interaction. Blue halo around the residue: the solvent accessible surface (SAS) of an interacting residue. The blue halo was proportional to SAS. Green dashed line: H-bond with an amino acid main chain. Blue dashed line: H-bond with an amino acid side chain. Pink dashed line: charge interaction.

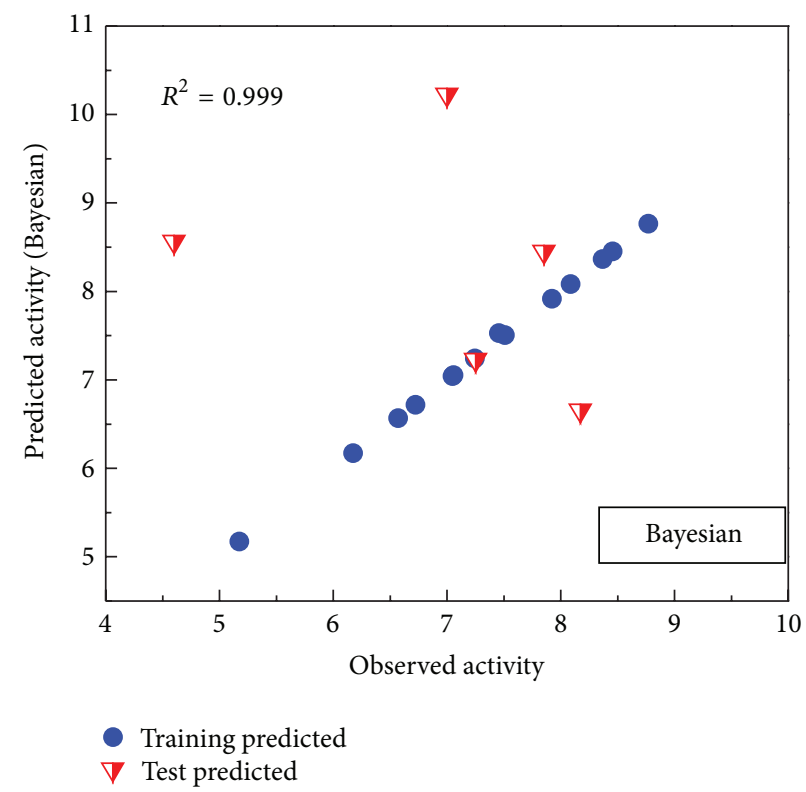

FIGURE 5: Ligand-based validation: Bayesian network. 18 ligands were randomly divided into 13 training sets and 5 test sets. $R^{2}=0.999$. 

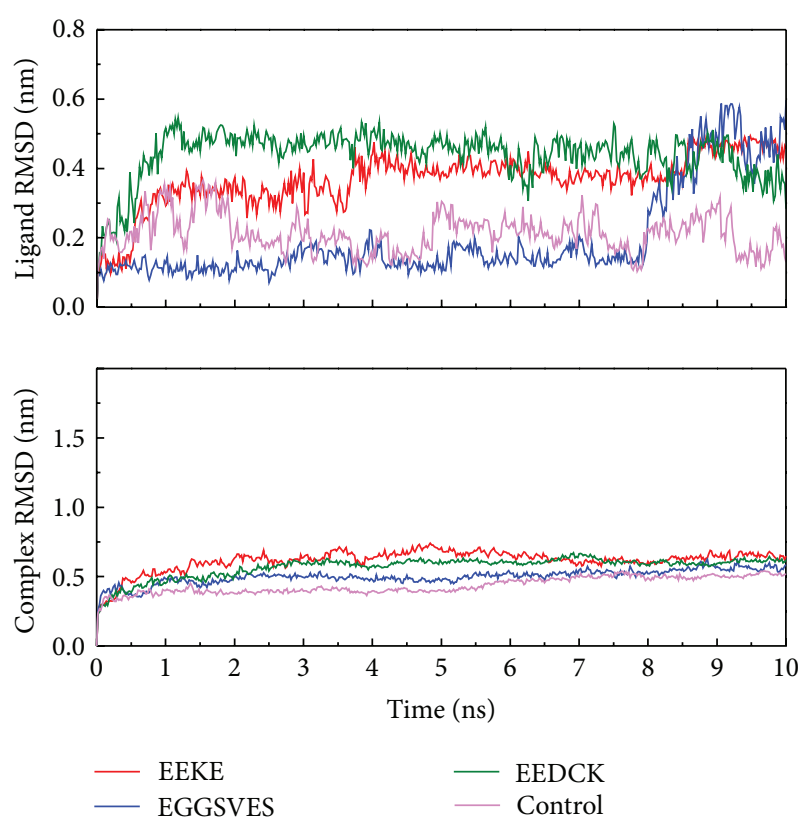

FIGURE 6: Ligand and complex root mean square deviation (RMSD). Although each ligand alone had larger deviation, the corresponding ligand-protein complex was relatively stable.
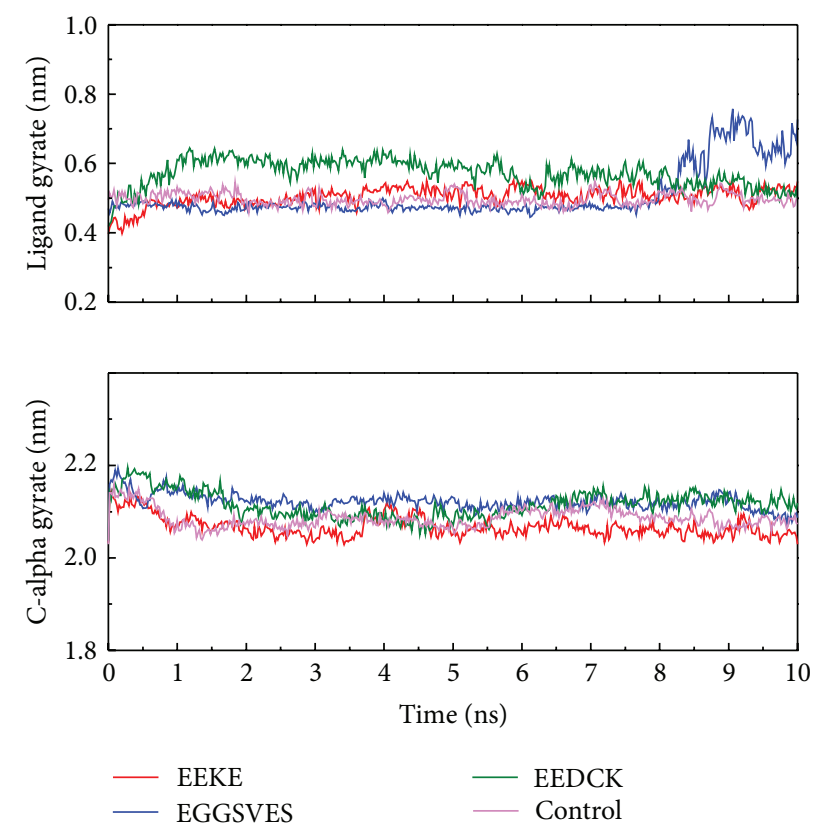

FIGURE 7: Ligand and C-alpha gyrate. Only EGGSVES had larger gyrate value after $8 \mathrm{~ns}$, other peptides or the complexes were stable in contrast.

set and test set. The data of descriptors and $\mathrm{pIC}_{50}$ were discretized to reduce bias distribution [68]. They were discretized into a maximum of three categories. The training set was defined as linear regression analysis for every $\mathrm{pIC}_{50}$ category after data discretization [69]. We used Banjo package and Bayes Net Toolbox (BNT) package for simulation in our
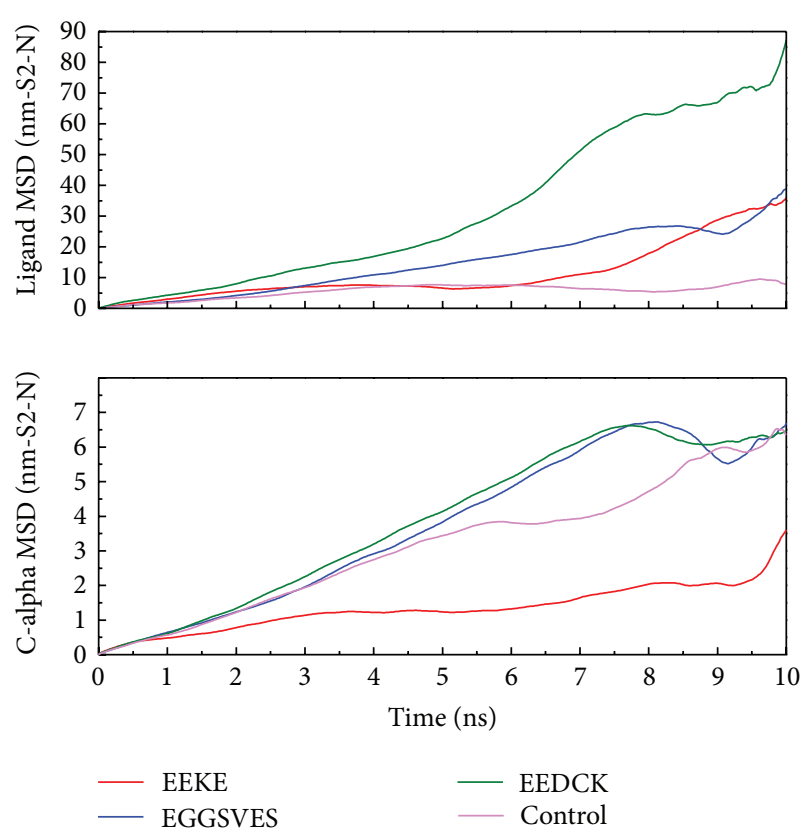

FIGURE 8: Ligand and C-alpha mean square deviation (MSD). All the ligands and complexes had predictable trends but had larger fluctuation after $8 \mathrm{~ns}$ relatively.

study. The 18 ligands were randomly divided into 13 training sets and 5 test sets for further validation.

2.6. Molecular Dynamics (MD) Simulation. We used Simulation module in DS 2.5 for MD simulation. The cytoplasmic status was simulated with transferable intermolecular potential 3P (TIP3P) water at $0.9 \% \mathrm{NaCl}$ concentration. Selected protein-ligand complexes from docking were conducted under minimization, heating, equilibration, and production. The minimization phase included 500 steps of deepest descent and 500 steps of conjugated gradient. The heating time from $50 \mathrm{~K}$ to $310 \mathrm{~K}$ was $50 \mathrm{ps}$. The equilibration time at $310 \mathrm{~K}$ was $150 \mathrm{ps}$. The production time with constant temperature dynamics method was $10 \mathrm{~ns}$. The temperature decay time was $0.4 \mathrm{ps}$. The Analyze Trajectory module was used to analyze total energy, root mean square deviations (RMSD), gyrate, mean square deviation (MSD), and solvent accessible surface (SAS) for each ligand and protein-ligand complex. We also illustrated cluster analysis to observe structure features during MD. Illustration of disordered protein was shown to exclude disordered residues [70, 71]. We used LigandPath module to estimate the possible pathway for each ligand. A surface probe was set at $6 \AA$, and minimum clearance was set at $3 \AA$.

\section{Results}

3.1. Homology Modeling. The overall identity of sequence alignment between MCIR and template was $49.8 \%$. The overall similarity was $72.4 \%$ (Figure 1). Ramachandran plot of MC1R-modeled structure indicated that $84.7 \%$ of residues 

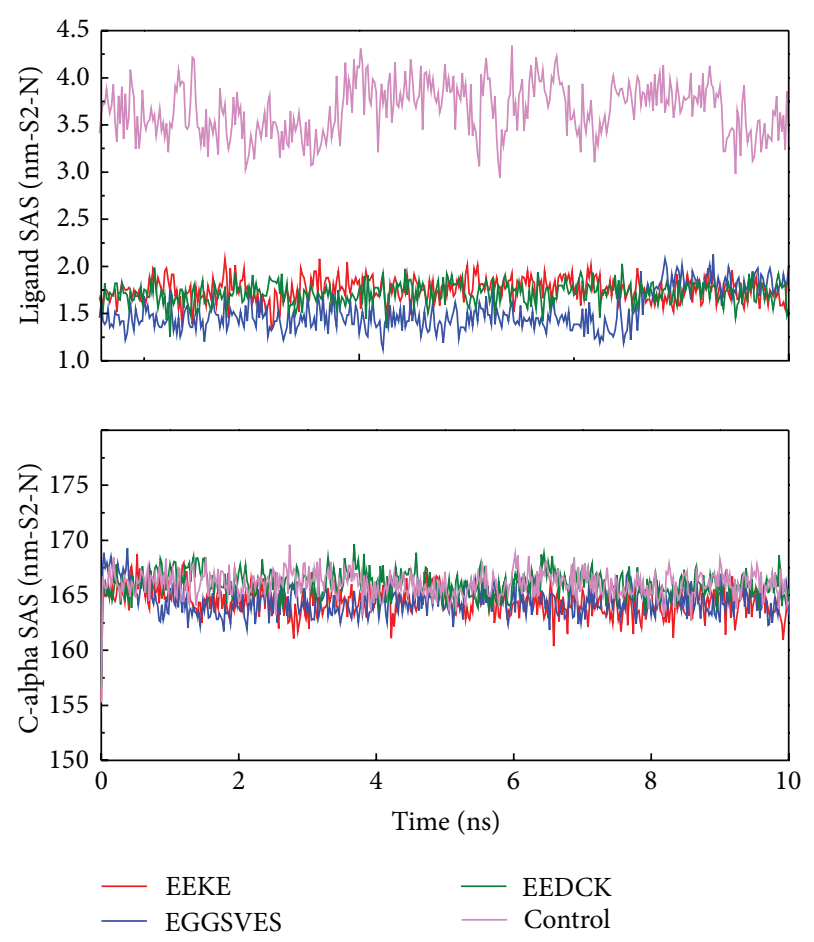

FIGURE 9: Ligand and C-alpha solvent accessible surface (SAS). The control ligand had larger SAS value compared with other ligands, but its corresponding complex was almost consistent to other complexes.

were in the favored region, $9.9 \%$ were in the allowed region, and only $5.3 \%$ were in the disallowed region (Figure 2 ).

3.2. Structure-Based Virtual Screening. Dock score, BNT, -PLP1, -PLP2, and -PMF for the top 10 peptides ranked by Dock score were listed in Table 1. Integrating these data, we selected 3 following peptides: Glu-Glu-Lys-Glu (EEKE), and Glu-Gly-Gly-Ser-Val-Glu-Ser (EGGSVES), GluGlu-Asp-Cys-Lys (EEDCK) as candidates for further investigation (Figure 3). Docking poses of EEKE, EGGSVES, EEDCK, and the control (HFRW) with MC1R were illustrated in Figure 4. EEKE formed H-bond with Ala88 and Arg89 and formed charge interaction with Arg89 (Figure 4(a)). EGGSVES formed H-bond with Ala88 and Arg89 and formed charge interaction with Arg89 (Figure 4(b)). EEDCK formed charge interaction with Arg89 (Figure 4(c)). The control formed H-bond with Ala88 and Arg89 (Figure 4(d)).

3.3. Ligand-Based Validation. We illustrated the correlation of observed and predicted activities using the BNT model. The $R^{2}$ value of 0.999 indicated that it is a highly reliable model (Figure 5).

3.4. Molecular Dynamics (MD) Simulation. We analyzed MD trajectories which were generated by Gromacs. Root mean square deviation (RMSD) showed the deviation from the starting structure of each ligand or complex to the end of MD. EGGSVES had larger deviation after $8 \mathrm{~ns}$, but the corresponding ligand-protein complex was relatively stable in the same period. Other peptides were stable during $10 \mathrm{~ns}$ $\mathrm{MD}$ in contrast (Figure 6). gyrate, or radius of gyration, measured the distance of the atoms relative to the center of each mass. gyrate indicated the compact degree of each ligand or complex. Interestingly, EGGSVES had larger gyrate value after $8 \mathrm{~ns}$, but the corresponding complex was also relatively stable. Other peptides were stable during $10 \mathrm{~ns} \mathrm{MD}$ in contrast (Figure 7). Mean square deviation (MSD) measured the movement of atoms from their initial positions to the end of MD. MSD indicated the trend of each ligand or complex during MD. All the ligands and complexes had different line graphs, but the long-term trends could be predictable (Figure 8). Solvent accessible surface (SAS) measured the surface area of each ligand or complex in contact with the water. Although the control ligand had larger SAS value compared with other ligands, but the corresponding complex was almost consistent to other complexes (Figure 9). In addition, total energy of each ligand or complex means the total energy of atoms during MD. The total energy would fluctuate, but overall trend was consistent (Figure 10). We performed cluster analysis with RMSD values to identify the representative structure of the complex. The cluster analysis could identify two adjacent structure features for each complex during 5-10 ns MD. EEDCK ligand-protein complex had fluctuated structure features, indicated the complex had undergone many tiny changes (Figure 11). Most residues of MC1R-modeled structure were not in the disordered region (Figure 12). Different ligand pathways for EEKE, EGGSVES, and the control bound with MC1R were illustrated. EEDCK was not shown due to out of the criteria mentioned in materials and methods (Figure 13).

\section{Discussion}

4.1. Compound Database. MC1R is a peptide receptor, so we utilized the PepBank which was established by Massachusetts General Hospital, Harvard University, to conduct MC1R lead peptide screening. The PepBank database has contained nearly 20000 bioactive peptides. It is a useful and convenient peptide database.

4.2. Homology Modeling. The high percentage of identity and similarity of sequence alignment between MC1R (Q01726) and template (2IQP) indicated that the sequence alignment was reasonable. The high percentage of residues in the favored and allowed region indicated that the MC1R-modeled structure was reliable.

4.3. Structure-Based Virtual Screening. His-Phe-Arg-Trp (HFRW) is the most common key motif for MC1R. We originally expected the outcome peptide sequence from virtual screening should be similar to the control (HFRW). However, Dock score, BNT, -PLP1, -PLP2, and-PMF of the top 10 candidates were almost better than the control. The top 3 candidates which we selected were EEKE, EGGSVES, and EEDCK. Their sequences were quite different from the control. We could speculate that these candidates at least 


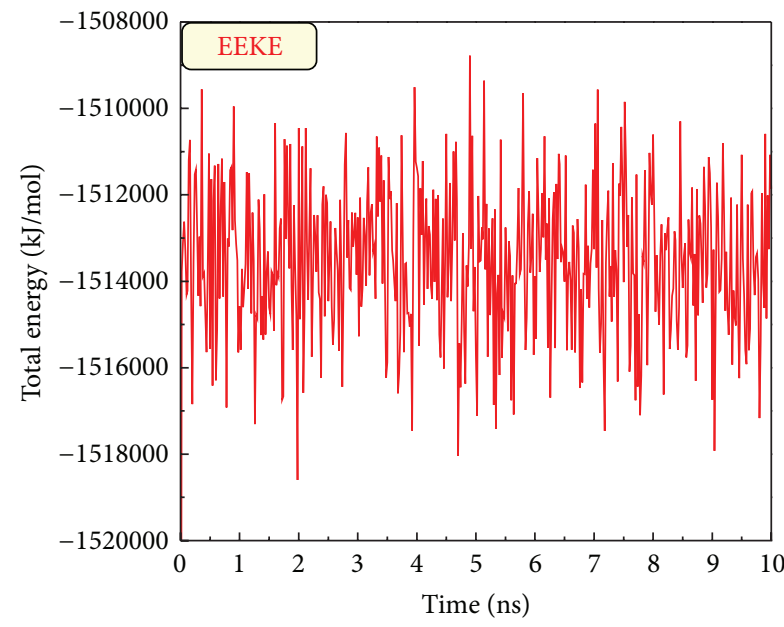

(a)

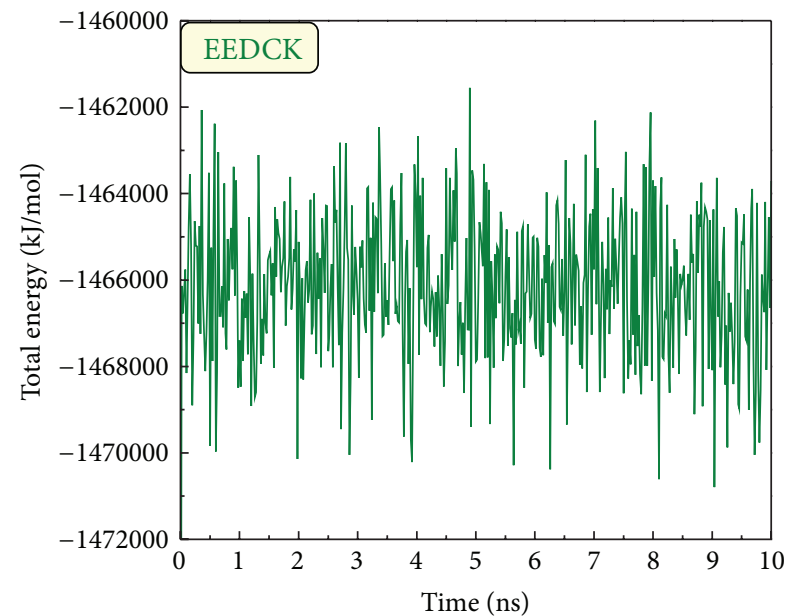

(c)

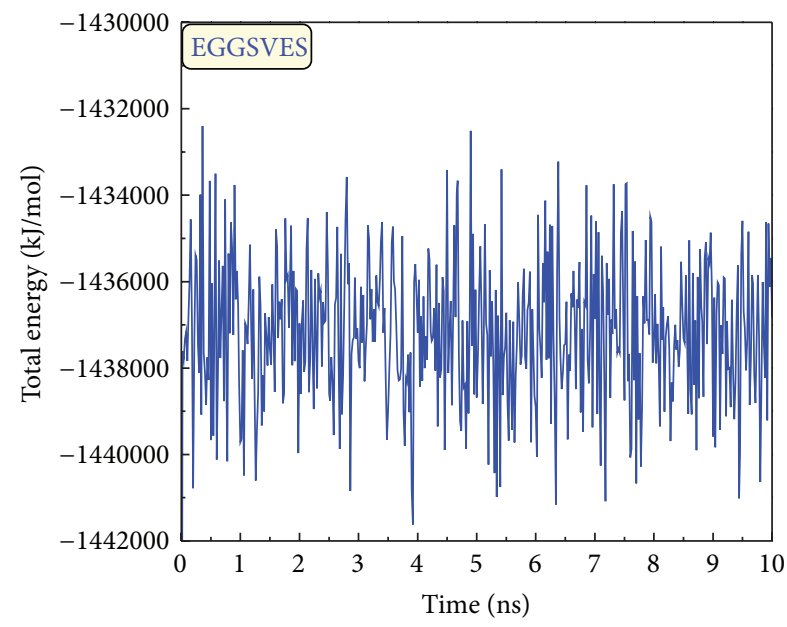

(b)

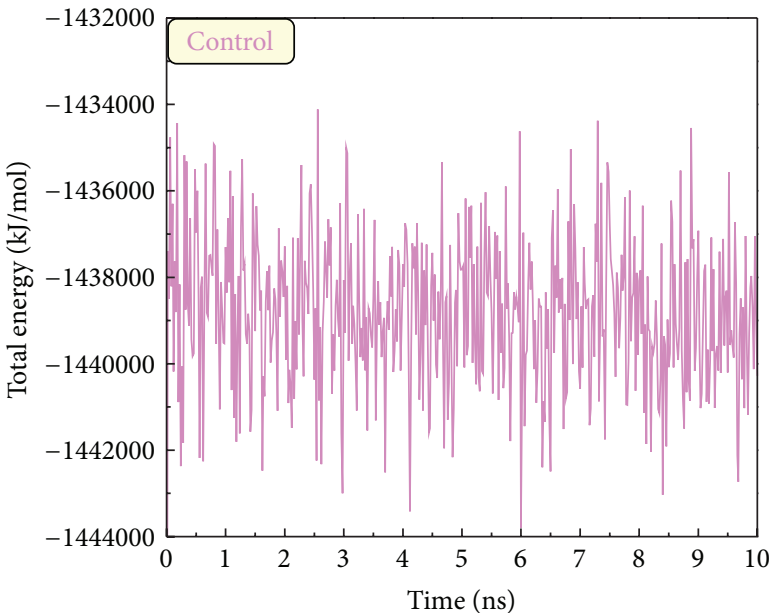

(d)

Figure 10: Total energy of (a) EEKE, (b) EGGSVES, (c) EEDCK, and (d) the control (HFRW).

TABLE 1: Top 10 candidates of scoring function from PepBank database screening.

\begin{tabular}{|c|c|c|c|c|c|}
\hline Name & Dock score & BNT & -PLP1 & -PLP2 & -PMF \\
\hline EEKE & 345.464 & 7.963191 & 37.91 & 36.24 & 32.59 \\
\hline EGGSVES & 338.21 & 6.979679 & 32.61 & 40.4 & 41.39 \\
\hline EEDCK & 337.005 & 9.512784 & 24.46 & 26.69 & 26.37 \\
\hline GEGEGSGG & 335.016 & 9.346013 & 42.84 & 51.79 & 29.34 \\
\hline SEEEAA & 322.144 & 12.351714 & 58.12 & 67.98 & 24.42 \\
\hline DSGVETS & 316.584 & 8.611215 & 13.43 & 19.48 & 31.47 \\
\hline EGEVGLG & 315.171 & 5.676182 & 28.59 & 30.23 & 22.78 \\
\hline EAGVDAA & 315.157 & 7.491065 & 24.74 & 25.56 & 30.21 \\
\hline DTAGQE & 311.701 & 6.382156 & 33.58 & 29.06 & 34.39 \\
\hline EEKE & 311.503 & 8.708929 & 44.54 & 48.58 & 27.17 \\
\hline His-Phe-Arg-Trp (HFRW) ${ }^{*}$ & 97.949 & 3.431413 & 32.8 & 26.9 & 28.15 \\
\hline
\end{tabular}

${ }^{*}$ Control. 


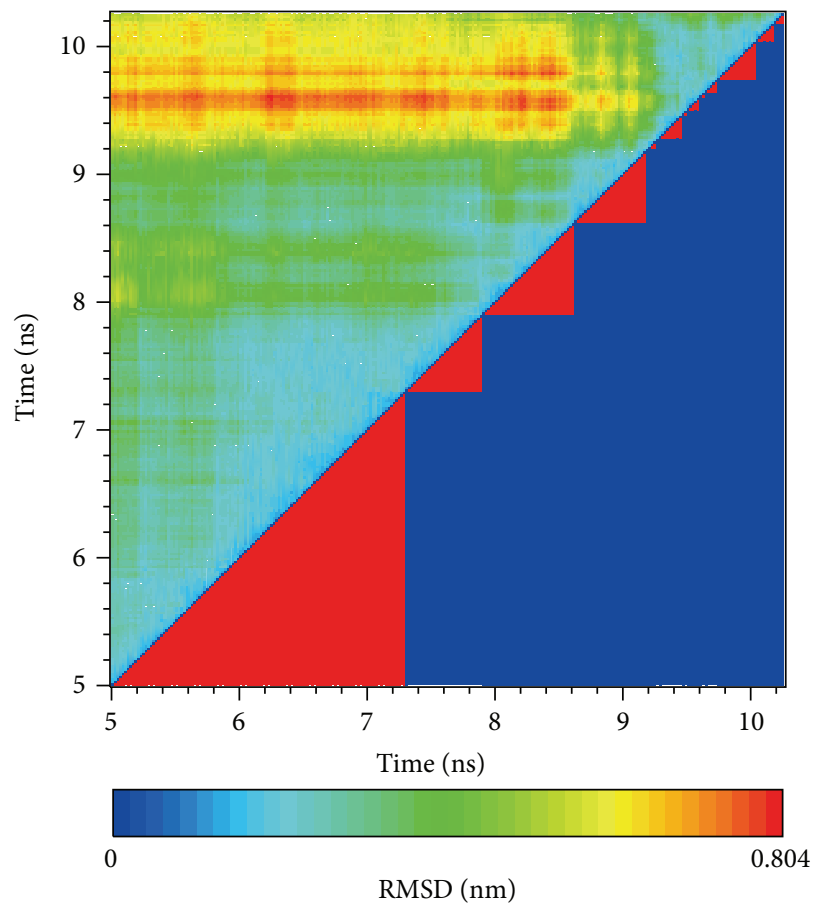

(a)

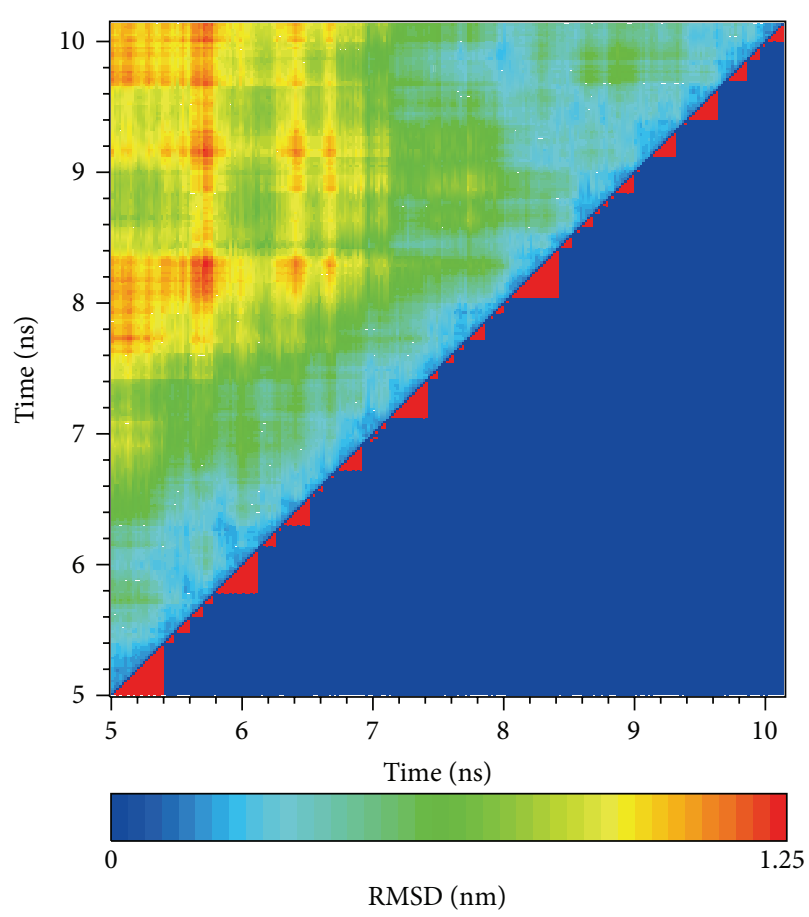

(c)

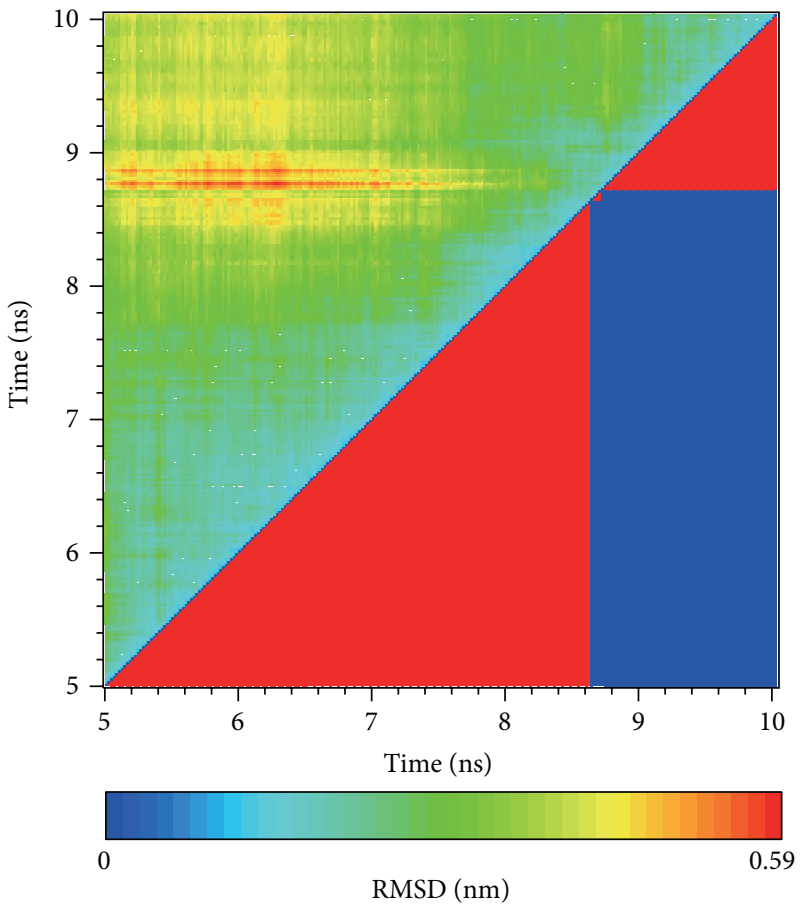

(b)

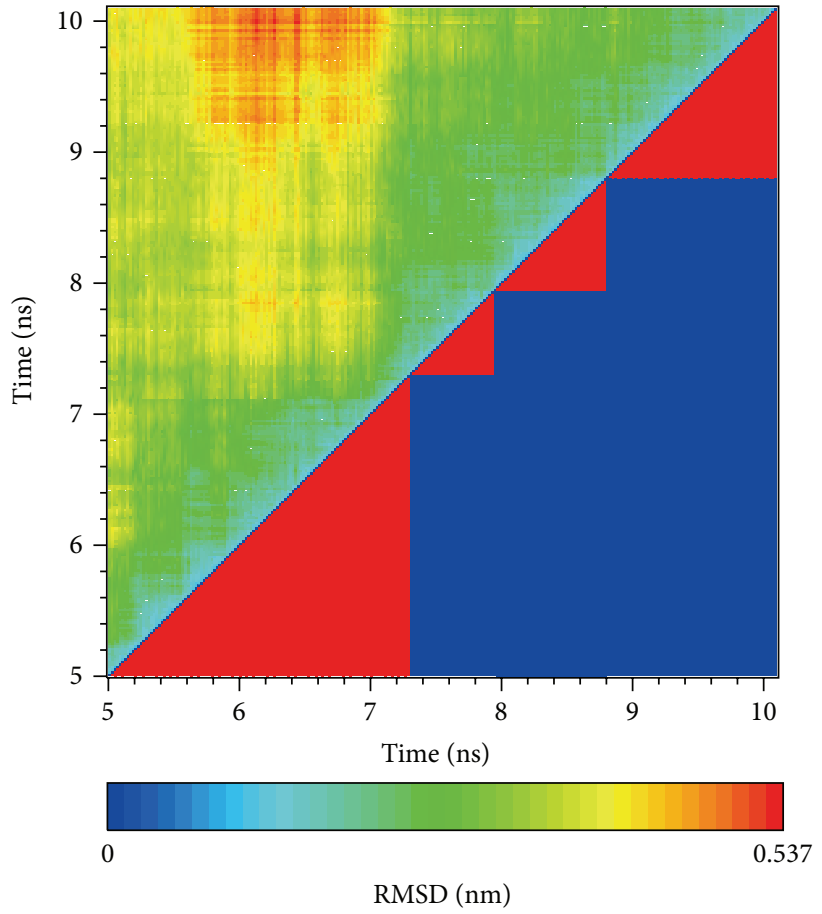

(d)

FIGURE 11: RMSD values (left upper portion) and graphical depiction of clusters (right lower portion). (a) EEKE, (b) EGGSVES, (c) EEDCK, and (d) the control (HFRW). 


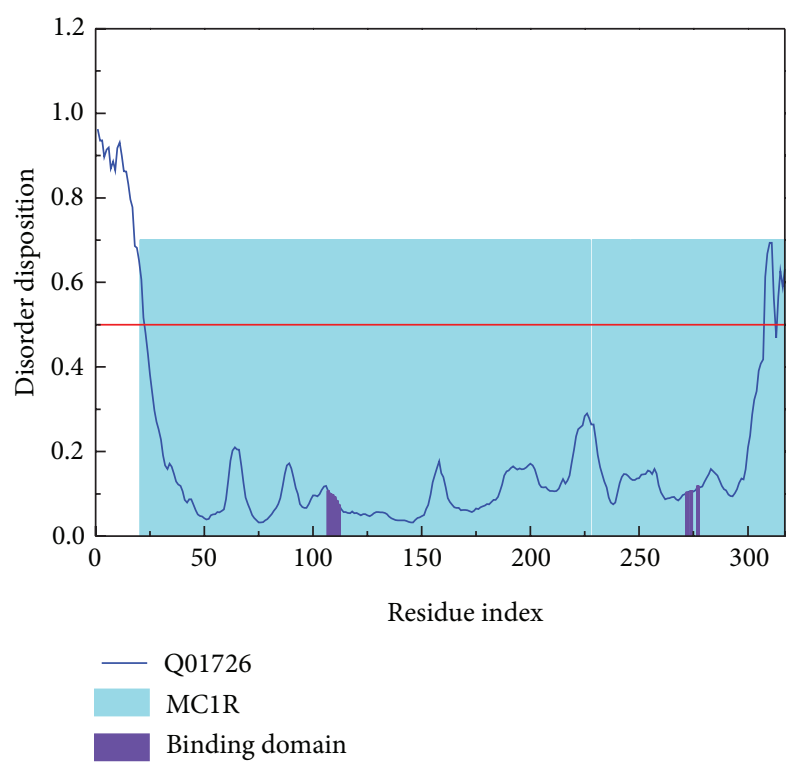

FIGURE 12: Disorder disposition of MC1R-modeled structure. Most residues are in the non-disordered region (below the red line).

had similar function as the control and might have better affinity for MClR. Comparing the docking poses of the top 3 candidates and the control with MCIR had the common finding. All of EEKE, EGGSVES, and the control formed H-bond with Ala88 and Arg89. All of EEKE, EGGSVES, and EEDCK formed charge interaction with Arg89. We could conclude that Ala88 and Arg89 were key residues for the top 3 candidates and the control.

4.4. Molecular Dynamics (MD) Simulation. RMSD, gyrate, MSD and, SAS were utilized to analyze the stability of each ligand or complex. Although some ligands were not stable during $\mathrm{MD}$, the ligand-protein complexes were stable relatively. So either of EEKE, EGGSVES, EEDCK, or HFRW could form stable complex with MC1R.

Further analyzing the figure of ligand RMSD, EEDCK had the largest average deviation than other candidates. Interestingly, the deviation of EEKE and EGGSVES exceeded EEDCK after 9 ns. However, analyzing the figure of complex RMSD, EEKE had the largest average deviation than other candidates. Although EGGSVES alone had larger deviation at 8-9 ns, the EGGSVES-MC1R complex did not have substantial change at the same time. It showed that deviation of individual ligand did not affect the stability of its corresponding complex.

Further analyzing the figure of ligand gyrate, EEDCK still had the largest average value than other candidates. Although EGGSVES alone had larger fluctuation at 8-9 ns, the EGGSVES-MCIR complex (c-alpha) did not have substantial change at the same time. It showed that gyrate of individual ligand did not affect the stability of its corresponding complex, either.

From the additional analysis of the figure of ligand MSD, EEDCK still had the largest deviation than other candidates.

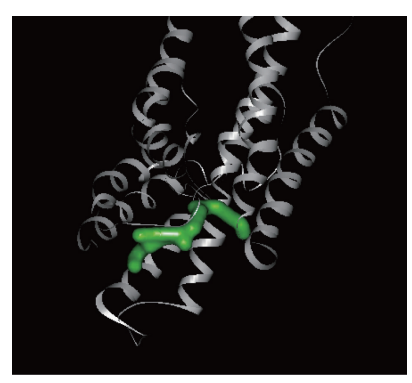

(a)

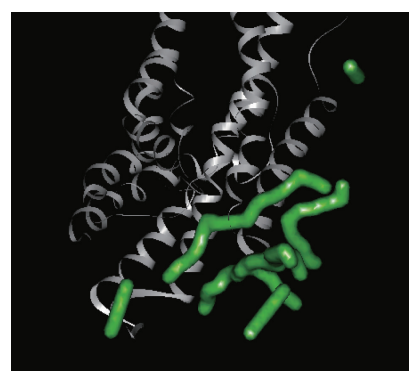

(b)

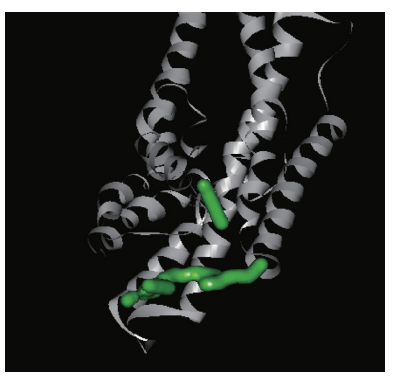

(c)

FIGURE 13: 3D simulation of ligand pathway for (a) EEKE, (b) EGGSVES, and (c) the control (HFRW) bound with MC1R. EEDCK is not shown here.

However, from results of the complex (c-alpha) MSD, EEKE had the lowest average deviation than other candidates. We speculated that EEKE-MC1R complex vibrated back and forth contributing to distinct presentation in complex RMSD and c-alpha MSD. EGGSVES vibrated in opposite direction might explain the upward slope in ligand RMSD and the downward slope in ligand MSD at 8-9 ns.

Further analyzing ligand SAS, the control had the largest average value than the 3 candidates. The result might be related to the hydrophobic side chain of the control.

Further analyzing the figure of total energy, EEKE had the lowest total energy $(-1514000 \mathrm{~kJ} / \mathrm{mol})$, and EGGSVES had the highest total energy $(-1437000 \mathrm{~kJ} / \mathrm{mol})$. We speculated that EEKE-MC1R complex only vibrated back and forth contributing to the lowest total energy.

When individual ligand bound to MC1R, MD was convenient to analyze the change of the ligand or the ligandprotein complex. MD could evaluate whether the ligand or the complex was stable or not under dynamic condition. MD might help us understand what happened during conjugation of the ligand and protein. Comparing the figures of RMSD 
and gyrate, EGGSVES had larger change after $8 \mathrm{~ns}$. The change implied that the structure of EGGSVES underwent some kind of deviation or even translocation. This change did not affect the conjugation of EGGSVES with MC1R because the ligand-protein complex was stable relatively. Comprehensive assessment of the methods of MD, such as RMSD, gyrate, MSD, SAS, and total energy, indicated that all the 3 candidates and the control could form stable complexes with MC1R [72-81].

\section{Conclusion}

$\mathrm{MC1R}$ is important for skin tanning. $\alpha \mathrm{MSH}$ is a melanotropin which can bind to MC1R. His-Phe-Arg-Trp (HFRW) is a key motif for conjugating with MC1R. We tried to find potential peptides that can also bind to MC1R by virtual screening of peptide database. Glu-Glu-Lys-Glu (EEKE), Glu-GlyGly-Ser-Val-Glu-Ser (EGGSVES), and Glu-Glu-Asp-Cys-Lys (EEDCK) had better affinity for MC1R. The binding affinity was further validated by molecular dynamics. Thus, we concluded that EEKE, EGGSVES, and EEDCK were more potent lead peptides for MC1R to resolve pigmentary disorders.

\section{Conflict of Interests}

The authors declare that there is no conflict of interests regarding the publication of this paper.

\section{Acknowledgments}

This study was supported by Grants from the National Science Council of Taiwan (NSC102-2325-B039-001 and NSC102-2221-E-468-027-), Asia University (ASIA101-CMU2, 102-Asia-07), and China Medical University Hospital (DMR-103-001, DMR-103-058, and DMR-103-096). This study was also supported in part by Taiwan Department of Health Clinical Trial and Research Center of Excellence (DOH102-TD-B-111-004) and Taiwan Department of Health Cancer Research Center of Excellence MOHW103-TD-B-11103.

\section{References}

[1] B. E. Johnson, G. Mandell, and F. Daniels Jr., "Melanin and cellular reactions to ultraviolet radiation," Nature, vol. 235, no. 57, pp. 147-149, 1972.

[2] R. Cui, H. R. Widlund, E. Feige et al., "Central role of p53 in the suntan response and pathologic hyperpigmentation," Cell, vol. 128, no. 5, pp. 853-864, 2007.

[3] J. Y. Lin and D. E. Fisher, "Melanocyte biology and skin pigmentation," Nature, vol. 445, no. 7130, pp. 843-850, 2007.

[4] D. E. Fisher and W. D. James, "Indoor tanning-science, behavior, and policy," The New England Journal of Medicine, vol. 363, no. 10, pp. 901-903, 2010.

[5] A. V. Schally, A. Arimura, and A. J. Kastin, "Hypothalamic regulatory hormones," Science, vol. 179, no. 4071, pp. 341-350, 1973.

[6] L. Proulx-Ferland, F. Labrie, and D. Dumont, "Corticotropinreleasing factor stimulates secretion of melanocyte-stimulating hormone from the rat pituitary," Science, vol. 217, no. 4554, pp. 62-63, 1982.

[7] T. A. Lugcr, T. Scholzen, and S. Grabbe, "The role of amelanocyte-stimulating hormone in cutaneous biology," Journal of Investigative Dermatology Symposium Proceedings, vol. 2, no. 1, pp. 87-93, 1997.

[8] A. B. Lerner and J. S. McGuire, "Melanocyte-stimulating hormone and adrenocorticotrophic hormone. Their relation to pigmentation," The The New England Journal of Medicine, vol. 270, pp. 539-546, 1964.

[9] J. I. Harris and A. B. Lerner, "Amino-acid sequence of the $\alpha$ melanocyte-stimulating hormone," Nature, vol. 179, no. 4574, pp. 1346-1347, 1957.

[10] A. Singh, A. Wilczynski, J. R. Holder et al., "Incorporation of a bioactive reverse-turn heterocycle into a peptide template using solid-phase synthesis to probe melanocortin receptor selectivity and ligand conformations by 2D1H NMR," Journal of Medicinal Chemistry, vol. 54, no. 5, pp. 1379-1390, 2011.

[11] N. M. Barkey, N. K. Tafreshi, J. S. Josan et al., "Development of melanoma-targeted polymer micelles by conjugation of a melanocortin 1 receptor (MC1R) specific ligand," Journal of Medicinal Chemistry, vol. 54, no. 23, pp. 8078-8084, 2011.

[12] C. K. Jayawickreme, J. M. Quillan, G. F. Graminski, and M. R. Lerner, "Discovery and structure-function analysis of $\alpha$ melanocyte-stimulating hormone antagonists," Journal of Biological Chemistry, vol. 269, no. 47, pp. 29846-29854, 1994.

[13] S. Lim, S. Li, C. Lee, C. Yoon, J. Baik, and W. Lee, "Minimization of MC1R selectivity by modification of the core structure of $\alpha$ MSH-ND," Chemistry and Biology, vol. 8, no. 9, pp. 857-870, 2001.

[14] N. Brabez, R. M. Lynch, L. Xu et al., "Design, synthesis, and biological studies of efficient multivalent melanotropin ligands: tools toward melanoma diagnosis and treatment," Journal of Medicinal Chemistry, vol. 54, no. 20, pp. 7375-7384, 2011.

[15] H. R. Bourne and E. C. Meng, "Rhodopsin sees the light," Science, vol. 289, no. 5480, pp. 733-734, 2000.

[16] K. Palczewski, T. Kumasaka, T. Hori et al., "Crystal structure of rhodopsin: a G protein-coupled receptor," Science, vol. 289, no. 5480, pp. 739-745, 2000.

[17] J. Vinós, K. Jalink, R. W. Hardy, S. G. Britt, and C. S. Zuker, "A G protein-coupled receptor phosphatase required for rhodopsin function," Science, vol. 277, no. 5326, pp. 687-690, 1997.

[18] A. J. Venkatakrishnan, X. Deupi, G. Lebon et al., "Molecular signatures of G-protein-coupled receptors," Nature, vol. 494, no. 7436, pp. 185-194, 2013.

[19] K. G. Mountjoy, L. S. Robbins, M. T. Mortrud, and R. D. Cone, "The cloning of a family of genes that encode the melanocortin receptors," Science, vol. 257, no. 5074, pp. 1248-1251, 1992.

[20] P. M. C. Lembo, E. Grazzini, J. Cao et al., "The receptor for the orexigenic peptide melanin-concentrating hormone is a Gprotein-coupled receptor," Nature Cell Biology, vol. 1, no. 5, pp. 267-271, 1999.

[21] B. Borowsky, M. M. Durkin, K. Ogozalek et al., "Antidepressant, anxiolytic and anorectic effects of a melanin-concentrating hormone-1 receptor antagonist," Nature Medicine, vol. 8, no. 8, pp. 825-830, 2002.

[22] C. Lalueza-Fox, H. Römpler, D. Caramelli et al., "A melanocortin 1 receptor allele suggests varying pigmentation among Neanderthals," Science, vol. 318, no. 5855, pp. 1453-1455, 2007. 
[23] N. I. Mundy, N. S. Badcock, T. Hart, K. Scribner, K. Janssen, and N. J. Nadeau, "Conserved genetic basis of a quantitative plumage trait involved in mate choice," Science, vol. 303, no. 5665, pp. 1870-1873, 2004.

[24] H. E. Hoekstra, R. J. Hirschmann, R. A. Bundey, P. A. Insel, and J. P. Crossland, "A single amino acid mutation contributes to adaptive beach mouse color pattern," Science, vol. 313, no. 5783, pp. 101-104, 2006.

[25] Y. Saito, H.-P. Nothacker, Z. Wang, S. H. S. Lin, F. Leslie, and O. Civelli, "Molecular characterization of the melaninconcentrating-hormone receptor," Nature, vol. 400, no. 6741, pp. 265-269, 1999.

[26] M. Sotomayor and K. Schulten, "Single-molecule experiments in vitro and in silico," Science, vol. 316, no. 5828, pp. 1144-1148, 2007.

[27] M. Levitt and A. Warshel, "Computer simulation of protein folding," Nature, vol. 253, no. 5494, pp. 694-698, 1975.

[28] B. Palsson, “The challenges of in silico biology," Nature Biotechnology, vol. 18, no. 11, pp. 1147-1150, 2000.

[29] C. von Mering, R. Krause, B. Snel et al., "Comparative assessment of large-scale data sets of protein-protein interactions," Nature, vol. 417, no. 6887, pp. 399-403, 2002.

[30] B. Palsson, "In silico biology through 'omics,' Nature Biotechnology, vol. 20, no. 7, pp. 649-650, 2002.

[31] H. Kitano, "Computational systems biology," Nature, vol. 420, no. 6912, pp. 206-210, 2002.

[32] B. di Ventura, C. Lemerle, K. Michalodimitrakis, and L. Serrano, "From in vivo to in silico biology and back," Nature, vol. 443, no. 7111, pp. 527-533, 2006.

[33] H. van de Waterbeemd and E. Gifford, "ADMET in silico modelling: towards prediction paradise?" Nature Reviews Drug Discovery, vol. 2, no. 3, pp. 192-204, 2003.

[34] T. Puzyn, B. Rasulev, A. Gajewicz et al., "Using nano-QSAR to predict the cytotoxicity of metal oxide nanoparticles," Nature Nanotechnology, vol. 6, no. 3, pp. 175-178, 2011.

[35] G. Liao, J. Wang, J. Guo et al., "In silico genetics: identification of a functional elements regulating HZ-E $\alpha$ gene expression," Science, vol. 306, no. 5696, pp. 690-695, 2004.

[36] M. Pellecchia, "Fragment-based drug discovery takes a virtual turn," Nature Chemical Biology, vol. 5, no. 5, pp. 274-275, 2009.

[37] J. Bajorath, "Integration of virtual and high-throughput screening," Nature Reviews Drug Discovery, vol. 1, no. 11, pp. 882-894, 2002.

[38] B. K. Shoichet, "Virtual screening of chemical libraries," Nature, vol. 432, no. 7019, pp. 862-865, 2004.

[39] E. Naylor, A. Arredouani, S. R. Vasudevan et al., "Identification of a chemical probe for NAADP by virtual screening," Nature Chemical Biology, vol. 5, no. 4, pp. 220-226, 2009.

[40] Y. Duan and P. A. Kollman, "Pathways to a protein folding intermediate observed in a 1-microsecond simulation in aqueous solution," Science, vol. 282, no. 5389, pp. 740-744, 1998.

[41] M. Karplus and G. A. Petsko, "Molecular dynamics simulations in biology," Nature, vol. 347, no. 6294, pp. 631-639, 1990.

[42] P. A. Bash, U. C. Singh, R. Langridge, and P. A. Kollman, "Free energy calculations by computer simulation," Science, vol. 236, no. 4801, pp. 564-568, 1987.

[43] J. P. Huelsenbeck, F. Ronquist, R. Nielsen, and J. P. Bollback, "Bayesian inference of phylogeny and its impact on evolutionary biology," Science, vol. 294, no. 5550, pp. 2310-2314, 2001.
[44] M. Karplus and J. A. McCammon, "Molecular dynamics simulations of biomolecules," Nature Structural Biology, vol. 9, no. 9, pp. 646-652, 2002.

[45] J. A. D’Orazio, T. Nobuhisa, R. Cui et al., “Topical drug rescue strategy and skin protection based on the role of Mclr in UVinduced tanning," Nature, vol. 443, no. 7109, pp. 340-344, 2006.

[46] J. Harms, S. Lautenschlager, C. E. Minder, and E. I. Minder, "An $\alpha$-melanocyte-stimulating hormone analogue in erythropoietic protoporphyria," The New England Journal of Medicine, vol. 360, no. 3, pp. 306-307, 2009.

[47] C. Y. Chen, "Weighted equation and rules-a novel concept for evaluating protein-ligand interaction," Journal of Biomolecular Structure and Dynamics, vol. 27, no. 3, pp. 271-282, 2009.

[48] K. W. Chang, T. Y. Tsai, K. C. Chen et al., "iSMART: an integrated cloud computing web server for traditional Chinese medicine for online virtual screening, de novo evolution and drug design," Journal of Biomolecular Structure and Dynamics, vol. 29, no. 1, pp. 243-250, 2011.

[49] T. Y. Tsai, K. W. Chang, and C. Y. Chen, "IScreen: world's first cloud-computing web server for virtual screening and de novo drug design based on TCM database@Taiwan," Journal of Computer-Aided Molecular Design, vol. 25, no. 6, pp. 525-531, 2011.

[50] C. Y. Chen, "A novel integrated framework and improved methodology of computer-aided drug design," Current Topics in Medicinal Chemistry, vol. 13, no. 9, pp. 965-988, 2013.

[51] W. I. Tou, S. S. Chang, C. C. Lee, and C. Y. Chen, "Drug design for neuropathic pain regulation from traditional Chinese medicine," Scientific Reports, vol. 3, p. 844, 2013.

[52] K. C. Chen, S. S. Chang, H. J. Huang et al., "Three-in-one agonists for PPAR-alpha, PPAR-gamma, and PPAR-delta from traditional Chinese medicine," Journal of Biomolecular Structure and Dynamics, vol. 30, no. 6, pp. 662-683, 2012.

[53] K. C. Chen, M. F. Sun, S. C. Yang et al., "Investigation into potent inflammation inhibitors from traditional Chinese medicine," Chemical Biology and Drug Design, vol. 78, no. 4, pp. 679-688, 2011.

[54] S. S. Chang, H. J. Huang, and C. Y. Chen, "Two birds with one stone? Possible dual-targeting H1N1 inhibitors from traditional Chinese medicine," PLoS Computational Biology, vol. 7, no. 12, Article ID e1002315, 2011.

[55] T. T. Chang, M. F. Sun, H. Y. Chen et al., "Screening from the world's largest TCM database against H1N1 virus," Journal of Biomolecular Structure and Dynamics, vol. 28, no. 5, pp. 773786, 2011.

[56] S. C. Yang, S. S. Chang, H. Y. Chen, and C. Y. C. Chen, "Identification of potent EGFR inhibitors from TCM database@Taiwan," PLoS Computational Biology, vol. 7, no. 10, Article ID e1002189, 2011.

[57] C. D. Fjell, J. A. Hiss, R. E. W. Hancock, and G. Schneider, "Designing antimicrobial peptides: form follows function," Nature Reviews, vol. 11, no. 1, pp. 37-51, 2012.

[58] B. K. Shoichet and B. K. Kobilka, "Structure-based drug screening for G-protein-coupled receptors," Trends in Pharmacological Sciences, vol. 33, no. 5, pp. 268-272, 2012.

[59] C. Mooney, N. J. Haslam, T. A. Holton et al., "PeptideLocator: prediction of bioactive peptides in protein sequences," Bioinformatics, vol. 29, no. 9, pp. 1120-1126, 2013.

[60] V. J. Hruby, "Designing peptide receptor agonists and antagonists," Nature Reviews, vol. 1, no. 11, pp. 847-858, 2002. 
[61] K. S. Lam, S. E. Salmon, E. M. Hersh, V. J. Hruby, W. M. Kazmierski, and R. J. Knapp, "A new type of synthetic peptide library for identifying ligand-binding activity," Nature, vol. 353, no. 6348 , pp. 82-84, 1991.

[62] R. A. Houghten, C. Pinilla, S. E. Blondelle, J. R. Appel, T. Dooley, and J. H. Cuervo, "Generation and use of synthetic peptide combinatorial libraries for basic research and drug discovery," Nature, vol. 353, no. 6348, pp. 84-86, 1991.

[63] C. Y. C. Chen, “TCM database@Taiwan: the world's largest traditional Chinese medicine database for drug screening in Silico," PLoS ONE, vol. 6, no. 1, Article ID e15939, 2011.

[64] T. Duchrow, T. Shtatland, D. Guettler, M. Pivovarov, S. Kramer, and R. Weissleder, "Enhancing navigation in biomedical databases by community voting and database-driven text classification," BMC Bioinformatics, vol. 10, article 1471, p. 317, 2009.

[65] L. Doedens, F. Opperer, M. Cai et al., "Multiple N -methylation of MT-II backbone amide bonds leads to melanocortin receptor subtype hMC1R selectivity: pharmacological and conformational studies," Journal of the American Chemical Society, vol. 132, no. 23, pp. 8115-8128, 2010.

[66] D. Baker and A. Sali, "Protein structure prediction and structural genomics," Science, vol. 294, no. 5540, pp. 93-96, 2001.

[67] B. R. Brooks, C. L. Brooks III, A. D. Mackerell Jr. et al., "CHARMM: the biomolecular simulation program," Journal of Computational Chemistry, vol. 30, no. 10, pp. 1545-1614, 2009.

[68] N. Friedman, M. Linial, I. Nachman, and D. Peer, "Using Bayesian networks to analyze expression data," Journal of Computational Biology, vol. 7, no. 3-4, pp. 601-620, 2000.

[69] J. Yu, V. A. Smith, P. P. Wang, A. J. Hartemink, and E. D. Jarvis, "Advances to Bayesian network inference for generating causal networks from observational biological data," Bioinformatics, vol. 20, no. 18, pp. 3594-3603, 2004.

[70] C. Y. Chen and W. I. Tou, "How to design a drug for the disordered proteins?" Drug Discovery Today, vol. 18, no. 19-20, pp. 910-915, 2013.

[71] W. I. Tou and C. Y. Chen, "May disordered protein cause serious drug side effect?” Drug Discovery Today, 2013.

[72] W. L. Liao and F. j. Tsai, "Personalized medicine: a paradigm shift in healthcare," BioMedicine, vol. 3, no. 2, pp. 66-72, 2013.

[73] F. J. Tsai, "Biomedicine brings the future nearer," BioMedicine, vol. 1, no. 1, p. 1, 2011.

[74] F. J. Tsai, "Rare diseases: a mysterious puzzle," BioMedicine, vol. 3, no. 2, p. 65, 2013.

[75] I. C. Chou, W. D. Lin, C. H. Wang et al., "Möbius syndrome in a male with XX/XY mosaicism," BioMedicine, vol. 3, no. 2, pp. 102-104, 2013.

[76] C. C. Lee, C. H. Tsai, L. Wan et al., "Increased incidence of Parkinsonism among Chinese with $\beta$-glucosidase mutation in central Taiwan," BioMedicine, vol. 3, no. 2, pp. 92-94, 2013.

[77] D. Y. Lin, F. J. Tsai, C. H. Tsai, and C. Y. Huang, "Mechanisms governing the protective effect of $17 \beta$-estradiol and estrogen receptors against cardiomyocyte injury," BioMedicine, vol. 1, no. 1, pp. 21-28, 2011.

[78] C. H. Wang, W. D. Lin, D. T. Bau et al., "Appearance of acanthosis nigricans may precede obesity: an involvement of the insulin/IGF receptor signaling pathway," BioMedicine, vol. 3, no. 2, pp. 82-87, 2013.

[79] Y. M. Chang, B. K. Velmurugan, W. W. Kuo et al., "Inhibitory effect of alpinate Oxyphyllae fructus extracts on Ang IIinduced cardiac pathological remodeling-related pathways in
H9c2 cardiomyoblast cells," BioMedicine, vol. 3, no. 4, pp. 148152, 2013.

[80] I. C. Chou, W. D. Lin, C. H. Wang et al., "Association analysis between Tourette's syndrome and two dopamine genes (DAT1, DBH) in Taiwanese children," BioMedicine, vol. 3, no. 2, pp. 8891, 2013.

[81] W. Y. Lin, H. P. Liu, J. S. Chang et al., "Genetic variations within the PSORS1 region affect Kawasaki disease development and coronary artery aneurysm formation," BioMedicine, vol. 3, no. 2, pp. 73-81, 2013. 


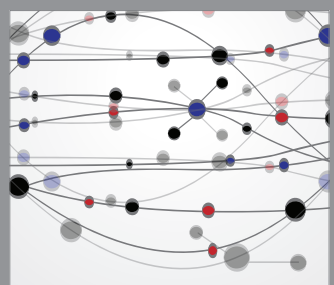

The Scientific World Journal
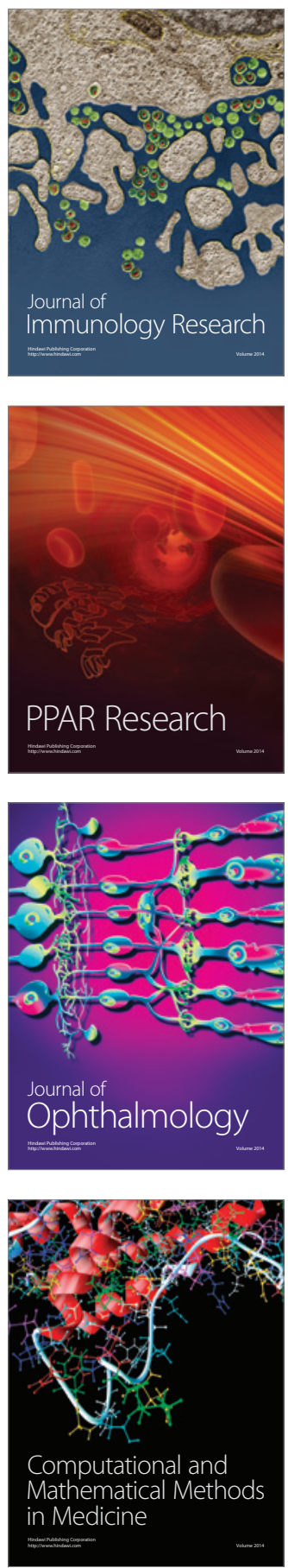

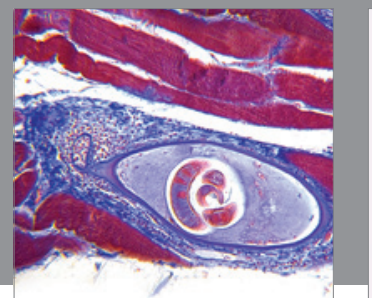

Gastroenterology

Research and Practice
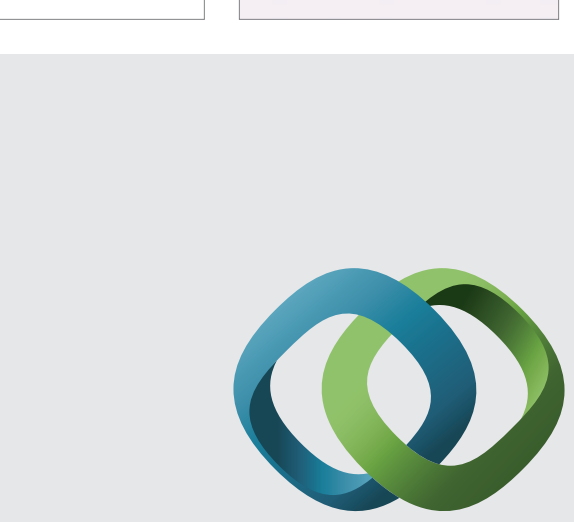

\section{Hindawi}

Submit your manuscripts at

http://www.hindawi.com
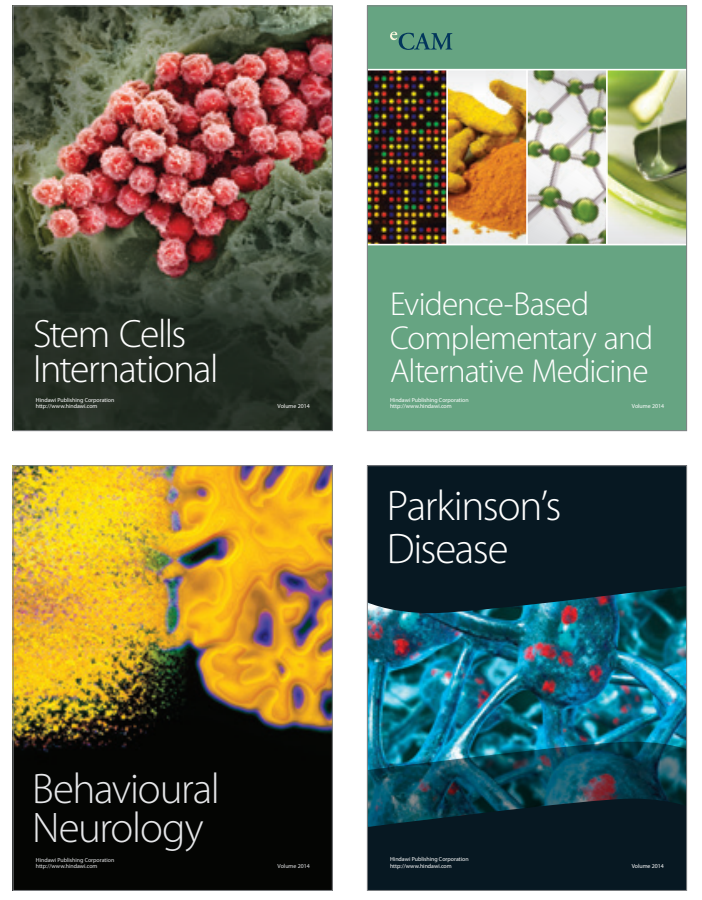
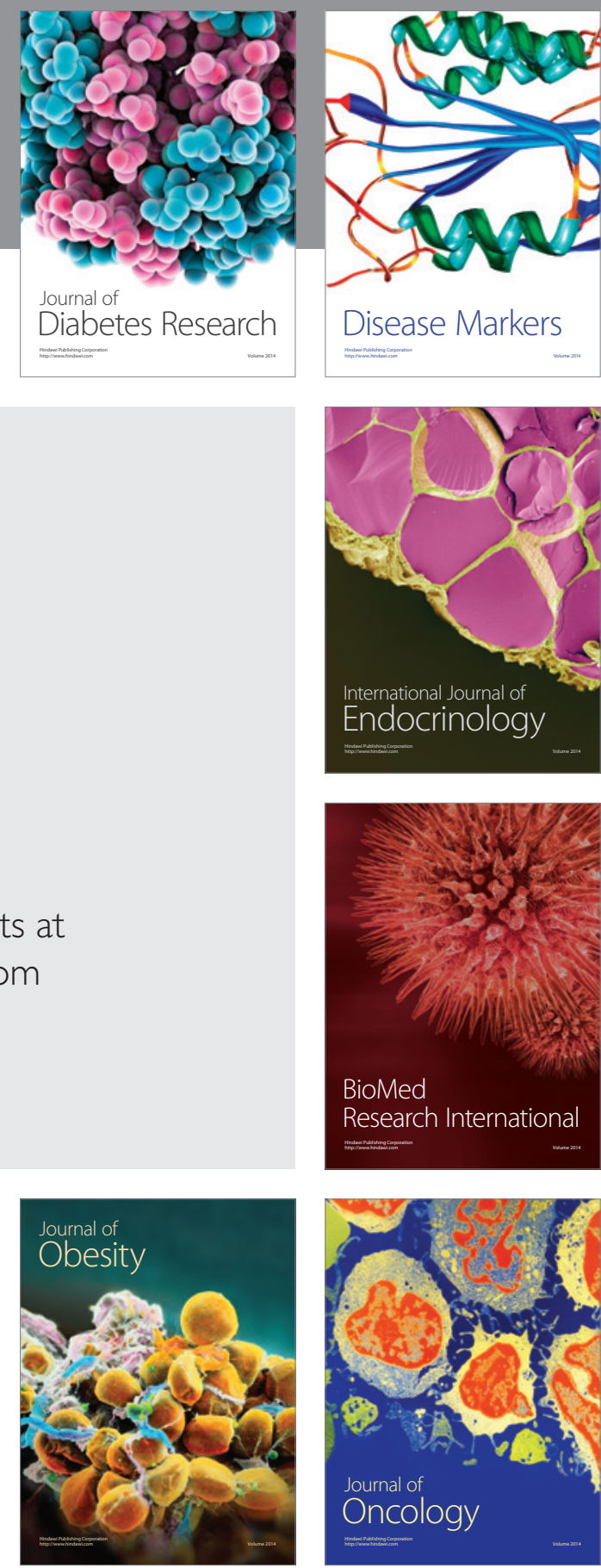

Disease Markers
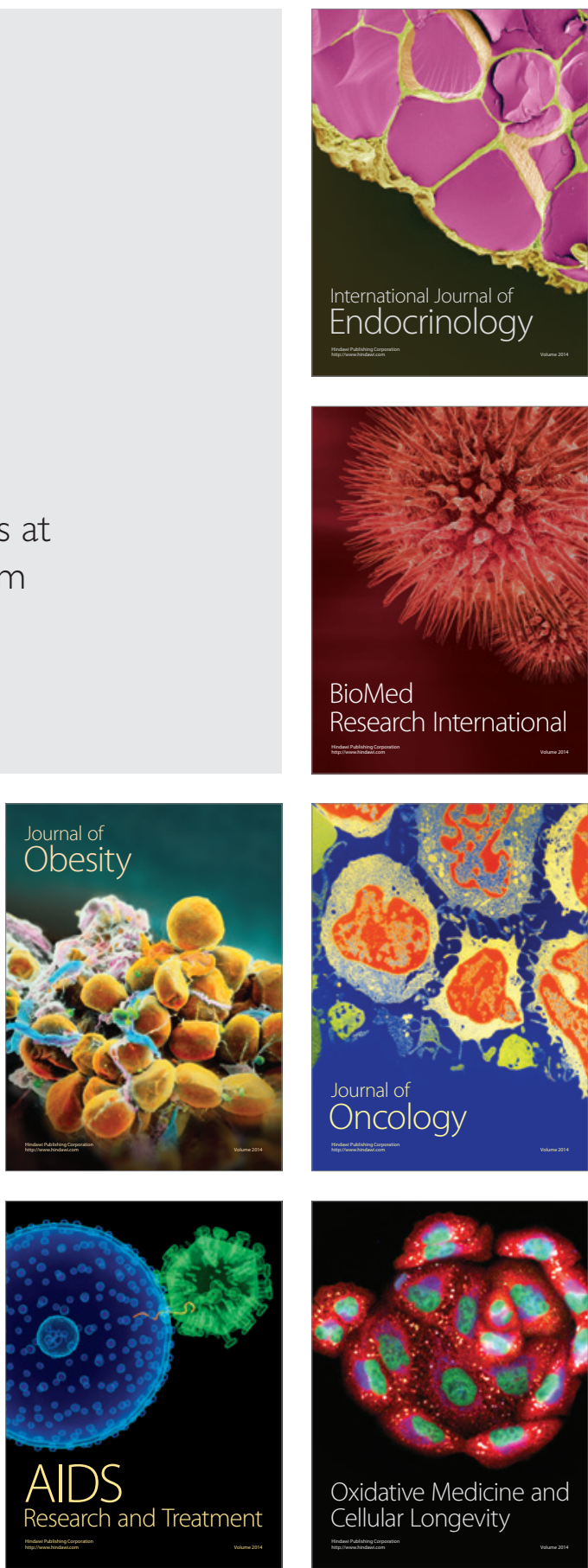